\title{
IMPLEMENTATION OF PROJECT-BASED LEARNING AT A MULTIDISCIPLINARY LEVEL OF THE SPECIALIZATION IN DESIGN AND MANUFACTURE OF MACHINES AND PROTOTYPES IN THE DEGREE OF MECHANICAL ENGINEERING
}

\author{
S. Montava-Jorda, V. Colomer Romero, A.V. Martínez Sanz, M.J. Reig Pérez, \\ F. López Esteve \\ Universidad Politécnica de Valencia (SPAIN)
}

\begin{abstract}
Since the implementation of the Bologna Process, universities have been incorporating into the European Higher Education Area, adapting and unifying educational criteria for all the European centers. Although mobility and bilingualism have been clearly promoted in universities by increasing performance in certain areas, it is necessary to improve other areas such as the implementation of novel active learning methodologies to promote deep learning. For this reason, Universitat Politècnica de València is putting faith in the implementation of active methodologies that integrate the development and acquisition of competences making the students the center of the learning-teaching process. Moreover, the lack of coordination among different subjects of the specialization in design and manufacture of machines and prototypes in the degree of Mechanical Engineering, is another important issue to be considered as it makes students to find difficulties in solving real problems.

In light of all these identified difficulties, the objective of this work is to design a project-based learning (PBL) model among the different subjects of the aforementioned specialization. The use of PBL will make students to actively participate in higher-level of cognitive processes. The most important premise when designing the project, in this case a gearbox casing, is the multidisciplinary aspects as the same project will have continuity and will cover different contents throughout the different subjects in the specialization. The methodology used for defining and implementing the PBL model consists of: (i) the identification of the current main difficulties; (ii) the definition of the PBL model; (iii) the identification of the necessary contents per subject to be applied in the solving process of the PBL model; and (iv) the evaluation/assessment of the PBL model implementation.
\end{abstract}

Finally, both the project and the different activities to be carried out in the different subjects involved in the PBL model are presented. In addition, the results obtained through a satisfaction survey performed by the students to collect their opinion will be also analysed to provide feedback for further improvement of the PBL model.

Keywords: Project-Based Learning, mechanical engineering, multidisciplinary project, machine and prototypes, design and manufacture, gearbox casing.

\section{INTRODUCTION}

Since the implementation of the Bologna Process, universities have been incorporating into the European Higher Education Area, adapting and unifying educational criteria for all the European centers. Although mobility and bilingualism have been clearly promoted in universities by increasing performance in certain areas, it is necessary to improve other areas such as the implementation of novel active learning methodologies to promote deep learning[1]. For this reason, Universitat Politècnica de València is putting faith in the implementation of active methodologies that integrate the development and acquisition of competences making the students the center of the learning-teaching process. Moreover, the lack of coordination among different subjects of the specialization in design and manufacture of machines and prototypes in the degree of Mechanical Engineering, is another important issue to be considered as it makes students to find difficulties in solving real problems.

\section{METHODOLOGY}

In light of all these identified difficulties, the objective of this work is to design a project-based learning (PBL) model among the different subjects of the aforementioned specialization. The use of PBL will make students to actively participate in higher-level of cognitive processes. The most important premise 
when designing the project, in this case a gearbox casing, is the multidisciplinary aspects as the same project will have continuity and will cover different contents throughout the different subjects in the specialization. The methodology used for defining and implementing the PBL model consists of: (i) the identification of the current main difficulties; (ii) the definition of the PBL model; (iii) the identification of the necessary contents per subject to be applied in the solving process of the PBL model; and (iv) the evaluation/assessment of the PBL model implementation.

\subsection{Identification of the main difficulties}

At present, many of the students in the last year of a degree encounter many difficulties when carrying out the Final Degree Project and the main cause is that they have not faced real problems and that there is no correct horizontal coordination between subjects [2]. In addition, Project-based Learning (hereinafter $\mathrm{ABP}$ ) has been gaining popularity and interest in both teachers and students due to the great impact on student learning [3] and there are different works that use it at a multidisciplinary level such as Serrano et al [4] Trasobares et al [5]. The greatest difficulty was finding a real project that could satisfy the competencies of each of the subjects involved in this work: (i) Theory and Design of Machines; (ii) Concurrent Engineering and (iii) Diagnosis and Correction of Faults in Machine Components.

\subsection{Definition of the PBL model}

The starting point was to decide the subject of the multidisciplinary project and it was decided to carry out the complete design of the casing of a speed reducer, from the calculation of machine elements and the efforts they generate to the manufacturing processes of the same as well as a study of finite elements to be able to calculate its resistance. In this case, the project includes 3 subjects of the specialty in design and manufacture of machines and prototypes in the degree of Mechanical Engineering that have already been mentioned above and whose characteristics are reflected in Table 1. The PDL model consists of 6 activities because It was decided to carry out 2 activities in each of the subjects. As can be seen, the activities of the third-year subject are compulsory for all students who take the mechanical engineering degree, however, the fourth-year subjects will only be carried out by those students who choose the specialty.

Table 1. Subjects involved in the PBL project.

\begin{tabular}{l|c|c|c|c}
\hline \hline \multicolumn{1}{c|}{ Subjects } & Year & Semester* & Type & $\begin{array}{c}\text { Number } \\
\text { Activities }\end{array}$ \\
\hline Machine Theory and Design & 3 & A+B & Mandatory & 2 \\
\hline Concurrent Engineering & 4 & A & Optional & 2 \\
\hline $\begin{array}{l}\text { Diagnosis and Correction of } \\
\text { Faults in Machine Components }\end{array}$ & 4 & B & Optional & 2 \\
\hline \hline
\end{tabular}

${ }^{*}$ A: From September to January, B: From February to June

In addition to determining the type of project to be developed, another important point was to maintain a certain coherence throughout the course of the same through the different subjects and that in each of them with the activities proposed they were expanding both the knowledge and the skills to the students. The authors of this work think that the selection of this topic can provide the students who study it with a more engineering point of view when it comes to solving real problems such as the one that has been raised, being able to extrapolate it to their Final Degree Projects.

\subsection{Identification of the contents by subject}

After reviewing each of the teaching guides of the different subjects involved in the PBL project, it was observed which were the main knowledge that the students are intended to acquire after taking them as shown in Table 2. 
Table 2. Knowledge of the subjects involved in the PBL project.

\begin{tabular}{l|l|l}
\hline \multicolumn{1}{c|}{ Machine Theory and Design } & Concurrent Engineering & $\begin{array}{l}\text { Diagnosis and Correction of Faults } \\
\text { in Machine Components }\end{array}$ \\
\hline $\begin{array}{l}\text { Introduction to the extensive field of } \\
\text { mechanical design of machine } \\
\text { components. }\end{array}$ & $\begin{array}{l}\text { Selection of materials and } \\
\text { manufacturing processes. }\end{array}$ & $\begin{array}{l}\text { Concept of stress intensity factor and } \\
\text { fracture toughness. }\end{array}$ \\
\hline Mechanical behaviour of materials. & $\begin{array}{l}\text { High-quality product design } \\
\text { techniques. }\end{array}$ & Crack growth models. \\
\hline $\begin{array}{l}\text { Static failure criteria under multiaxial } \\
\text { stresses. Fatigue design. }\end{array}$ & $\begin{array}{l}\text { Design oriented to } \\
\text { manufacture and assembly. }\end{array}$ & $\begin{array}{l}\text { Measurement of deformations and } \\
\text { displacements. }\end{array}$ \\
\hline $\begin{array}{l}\text { Criteria for dimensioning, design and } \\
\text { selection of components. }\end{array}$ & Process planning. & Evaluation of the tension state. \\
\hline $\begin{array}{l}\text { Modeling of mechanical systems for } \\
\text { vibration analysis. }\end{array}$ & - & $\begin{array}{l}\text { Experimental validation of behaviour } \\
\text { models of machines and elements. }\end{array}$ \\
\hline \hline
\end{tabular}

From this review it was possible to carry out a study in more detail to be able to propose each of the activities to be carried out in each of the subjects with the appropriate order and coherence so that the students achieve the objectives set in the foreseen time. In Table 3 you can see which the proposed activities and their order are depending on the subject.

Table 3. Activities to be carried out in the PBL project.

\begin{tabular}{|c|c|c|}
\hline Order & Subject & Activity \\
\hline 1 & Machine Theory and Design & Design of the kinematic chain of a gearbox. \\
\hline 2 & Machine Theory and Design & Obtaining the dimensions and reactions in the gearbox housing. \\
\hline 3 & Concurrent Engineering & Selection of materials and manufacturing processes for the gearbox housing. \\
\hline 4 & Concurrent Engineering & Analysis of the manufacturing process: transfer of dimensions. \\
\hline 5 & $\begin{array}{l}\text { Diagnosis and Correction of } \\
\text { Faults in Machine Components }\end{array}$ & Design and 3D modeling of the gearbox housing. \\
\hline 6 & $\begin{array}{l}\text { Diagnosis and Correction of } \\
\text { Faults in Machine Components }\end{array}$ & $\begin{array}{l}\text { Analysis and evaluation of finite elements of the gearbox housing: } \\
\text { deformations and state of stress. }\end{array}$ \\
\hline
\end{tabular}

Each of the activities will be briefly described below so that you can better understand what their objectives were.

\section{+ Activity 1. Design of the kinematic chain of a gearbox.}

Within the first activity there are students who may not choose the specialty in which the PBL project focuses, there will be no work groups and will work individually. Specifically, it is about carrying out the kinematic chain of the gearbox with the dimensioning of the shafts, bearings and gears with the KISSsys software, the program used in the subject of Machine Theory and Design.

\section{+ Activity 2. Obtaining the dimensions and reactions in the gearbox housing.}

Continuing with the previous task, the bearings of the different shafts will be aligned so that the dimensions of the casing can be obtained. Once with the definitive design, after entering the power and input speeds, the corresponding output speeds will be obtained as well as the loads on the gears and the reactions on the supports, which in this case are the bearings.

\section{+ Activity 3. Selection of materials and manufacturing processes for the gearbox casing.}

From activity 3 that will already be carried out in the subject of the first semester "A" of the fourth year and since these students are already part of this specialization, they will form groups of 3 to 5 participants. The activity will consist of analysing different gearbox housings to be able to select among all the manufacturing processes seen in the theoretical classes as well as its material. 


\section{Activity 4. Analysis of the manufacturing process: transfer of dimensions.}

In activity 4 , given that in activity 2 , some main dimensions were obtained, such as the distances between shafts or the distance between bearings, they will use the method of transfer of dimensions in order to obtain the rest of the necessary dimensions to be able to correctly define the dimensions of the Case.

\section{+ Activity 5. Design and 3D modeling of the gearbox housing.}

In activity 5 , after having obtained the dimensions of the casing, the casing model will be modeled in 3D space with the CAD software "Solidworks".

+ Activity 6. Analysis and evaluation by finite elements of the housing: deformations and stress state.

In activity 6 , the model generated in activity 5 will be imported into the CAE finite element software "ANSYS" and with the loads obtained in activity 2, a stress study will be carried out.

In Fig 1 we can see a graphic scheme that was made to be able to present to the students what the multidisciplinary PBL project "Design of a gearbox housing" would visually consist of.

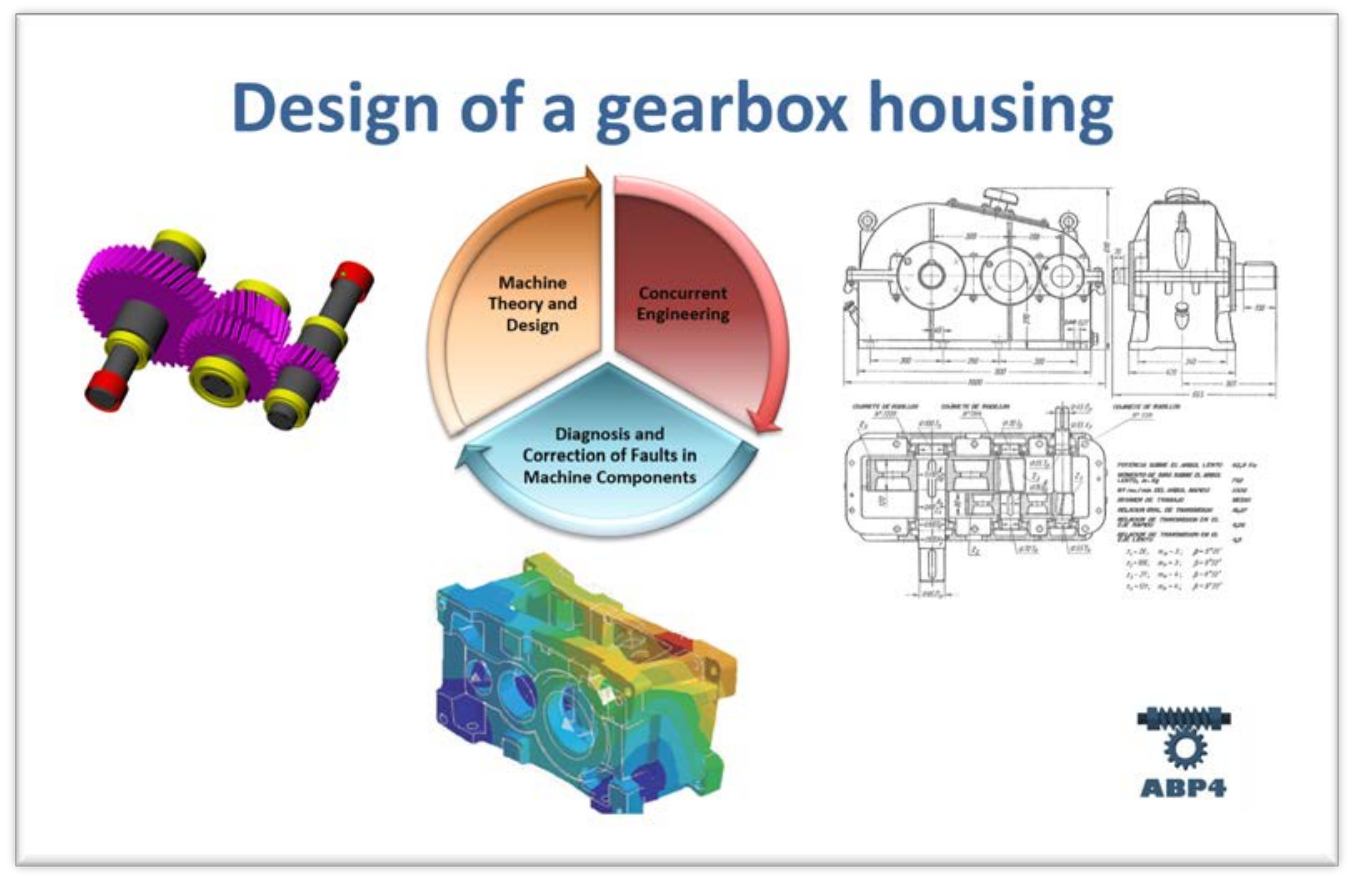

Figure 1. Graphic diagram of the PBL project "Design of a gearbox housing".

\subsection{Evaluation and assessment of the implementation}

As it is an interdisciplinary experience and that the number of students who will participate in the different activities will vary, the authors thought that the evaluation system had to be in the same way variable. As this is the first year of implementation, it was thought that the evaluation for activities 1 and 2 individually as one more task than those carried out in the subject and for the rest of the activities the group work for which they are prepared would be taken into account an evaluation rubrics.

Since it was the first year that this methodology was implemented in the Degree in Mechanical Engineering, specifically in the third year with the core subject of Machine Theory and Design, it was decided to carry out a presentation session of both the project and the PBL methodology. After the presentation, a questionnaire was carried out using the "Google Forms" application to analyze and evaluate a series of questions.

\section{RESULTS}

The questions of the opinion survey are detailed below as well as the results obtained from the 52 students who participated in the survey voluntarily. 


\subsection{Question 1: Did you know the Project-based Learning methodology (PBL)?}

When we analysed this question, we were surprised by the results of Fig. 2 with almost $83 \%$ of the interviewees, third-year students of the degree, did not yet know this type of active methodology, although it was to be expected since it was not long ago. is betting on the use of these methodologies from the Universitat Politècnica de València and in the first years of the degree it is more difficult to implement.

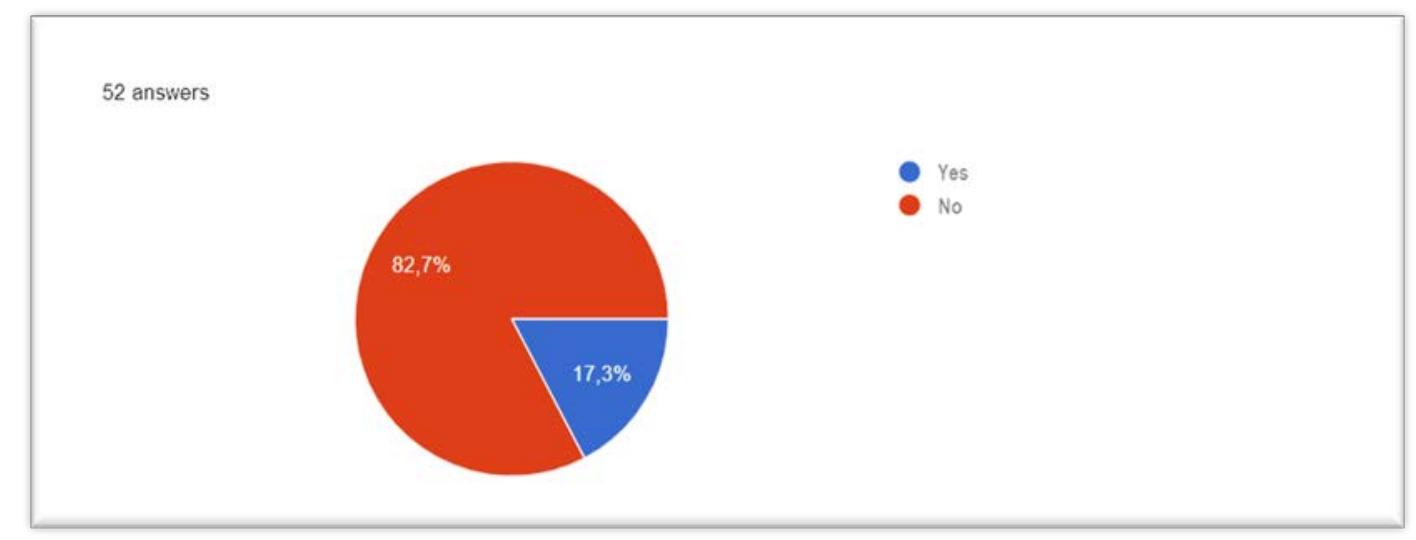

Figure 2. Results graph of the answers to question 1.

\subsection{Question 2: Do you think that the PBL is a good methodology to consolidate the concepts developed in the subject by applying them to a practical case?}

Despite not being aware of these methodologies after presenting and carrying out the activities, the responses were very positive, only $21,2 \%$ thought that with this methodology it was possible to consolidate the "LITTLE" concepts, but the rest 40,4\% "QUITE" and 38,5\% "A LOT OF" with which they confirmed what the authors thought that the PBL could be a good tool to consolidate concepts, as can be seen in Fig. 3.

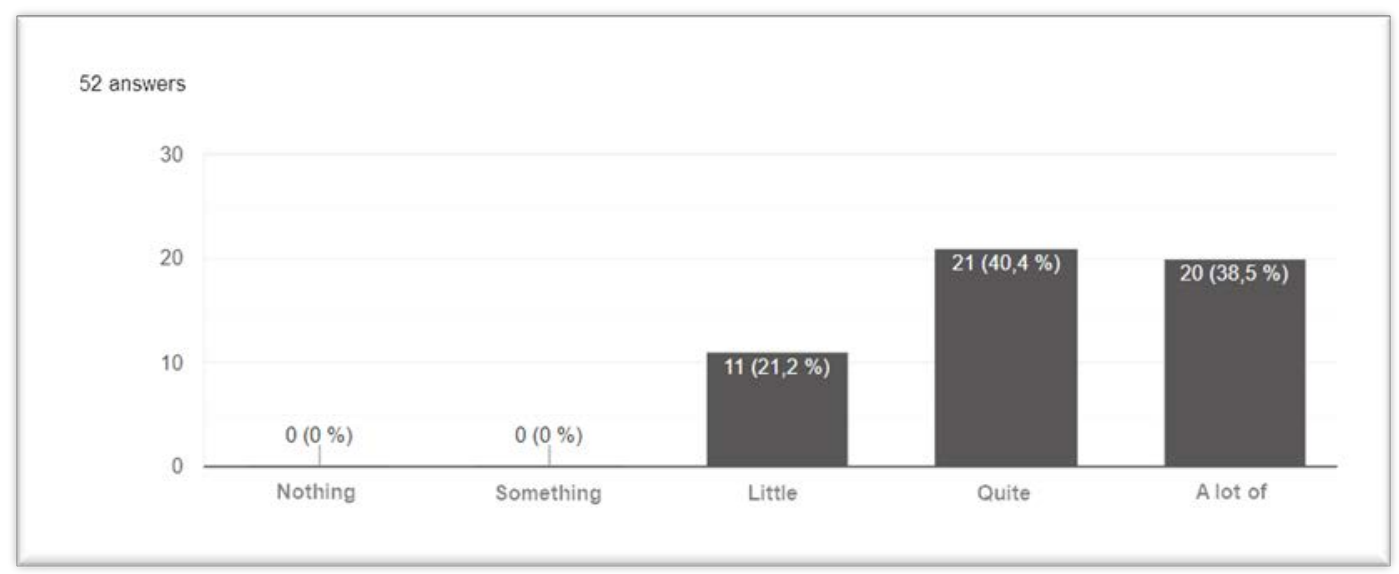

Figure 3. Results graph of the answers to question 2.

\subsection{Question 3: Would you like more subjects of the degree to work with the PBL methodology?}

The degree of satisfaction regarding this methodology among the interviewees was higher than expected, as can be seen in Fig. 4, incredibly, no one "NO" would like more subjects to use PBL and the rest of the answers were distributed between "MAYBE" with a 46,2\% and "YES" with 53,8\%. Again, these results confirm that the authors' objective is aligned with the opinion of the students, which is a good starting point to start a project of this style. 
52 answers
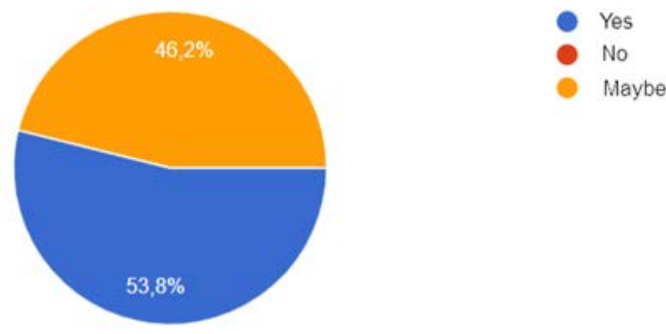

Figure 4. Results graph of the answers to question 3.

\subsection{Question 4: Do you find it interesting to be able to carry out the same interdisciplinary project between different subjects of the same mention of the Degree in Mechanical Engineering?}

Regarding the idea of applying this PBL methodology at an interdisciplinary level, again the opinions were surprising, appearing quite or very interesting to almost 3 out of every 4 students interviewed. If we analyse the results of Fig. 5, only 5,8\% thought it was "SOMETHING" interesting, 21,2\% thought it was "LITTLE" interesting, 46,2\% thought it was "QUITE" and 26,9\% "A LOT OF".

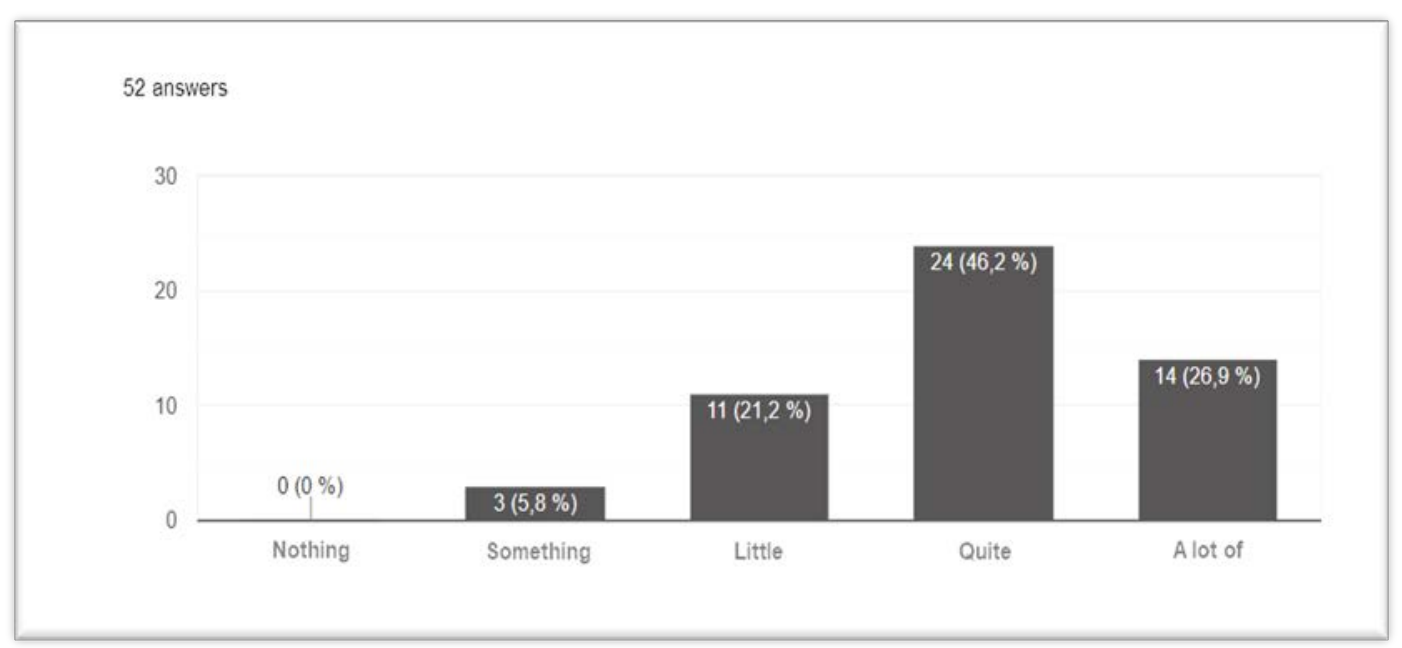

Figure 5. Results graph of the answers to question 4.

\subsection{Question 5: If you have any comments or recommendations, both positive and negative, you can indicate them in this question.}

Although this question was not mandatory to complete the survey, the evaluations were few but very positive, only 7 of 52 students (barely 13.5\%) gave their opinion about the project and whose responses are described in Table 4. 
Table 4. Different answers of the students to question 5.

\begin{tabular}{c|l}
\hline \hline Student & \multicolumn{1}{c}{ Answers } \\
\hline$A$ & $\begin{array}{l}\text { This is quite good, because at the end of the day it is more real in the professional field to do a project } \\
\text { than an exam. }\end{array}$ \\
\hline$B$ & $\begin{array}{l}\text { This would benefit a lot because we would carry out a real practical case and the implications of each } \\
\text { subject would be seen in the same project. This would prepare a lot for the world of work. }\end{array}$ \\
\hline$C$ & It is beneficial for us; we pose real problems. \\
\hline$D$ & $\begin{array}{l}\text { It would be very good to learn the fact of relating all the subjects of the career and not see the } \\
\text { concepts only in a theoretical way. }\end{array}$ \\
\hline$E$ & $\begin{array}{l}\text { I think it is a very good methodology to learn, much more than is learned from exams, really, although } \\
\text { sometimes it can be a bit overwhelming (opinion) if the work is quite complex. }\end{array}$ \\
\hline$F$ & $\begin{array}{l}\text { It seems to me a good way to learn practical knowledge that will be useful tomorrow in the } \\
\text { professional field. }\end{array}$ \\
\hline$G$ & $\begin{array}{l}\text { Very good idea. Moreover, if it could be included in an interdisciplinary way, it would be much more } \\
\text { interesting since GIM today requires more real methodologies than throwing up theory. }\end{array}$ \\
\hline \hline
\end{tabular}

\section{CONCLUSIONS}

In this article the PBL model that was launched in the specialization in design and manufacture of machines and prototypes of the Degree in Mechanical Engineering of the Polytechnic University of Valencia has been presented and it is intended to evaluate the results of the next year when the students started project with the third year subject the new fourth year subjects involved.

The main objective of this work is to be able to improve students' skills when solving real problems such as those that may arise in their Final Degree Project or when they enter the world of work using ProjectBased Learning (PBL). The results of the opinion poll have been shown and the truth is that the data is very good, which suggests that the students want to use this methodology and that they like it. The answer to question 5, despite being few, has been very enriching for the authors.

\section{ACKNOWLEDGEMENTS}

This article has been supported by Universitat Politècnica de València, particularly by the Vice-rectorate for Digital Resources and Documentation (Vicerrectorado de Recursos Digitales y Documentación) and Vice-Rectorate for Studies, Quality and Accreditation (Vicerrectorado de Estudios, Calidad y Acreditación) under the Call for Learning + Teaching (Convocatoria A+D2019: Aprendizaje + Docencia. Proyectos de Innovación y Mejora Educativa) and Project Code: A157. The authors would like to acknowledge the support of the Institute of Educational Sciences (Instituto de Ciencias de la Educación), the Evaluation and Monitoring Commission for Educational Innovation and Improvement Projects (Comisión de Evaluación y Seguimiento de Proyectos de Innovación y Mejora Educativa (CESPIME) and Escuela Politécnica Superior de Alcoy.

\section{REFERENCES}

[1] Universia.es, "¿Cómo ha cambiado la educación en España con el Plan Bolonia?," 19/06/2018, 2018.

[2] P. J. M. Castejón, M. A. Renart, and M. C. P. Peñalver, "Los beneficios de la coordinación horizontal en la realización de los TFG para los alumnos de Grado en Administración y Dirección de Empresas," Revista de Investigación en Educación, vol. 11, no. 1, pp. 97-117, 2013.

[3] [J. Sánchez, "Qué dicen los estudios sobre el Aprendizaje Basado en Proyectos," Actualidad pedagógica, pp. 1-4, 2013.

[4] A. C. B. Serrano, A. C. Pascual, I. B. González et al., "¿ Y si Aplicamos el Aprendizaje basado en Proyectos de forma Interdisciplinar? Innovación e Investigación en la Mención de Atención a la Diversidad de la Facultad de Educación (Universidad de Zaragoza)."

[5] A. H. Trasobares, and R. L. Gilaberte, "Aplicación del aprendizaje basado en problemas (PBL) bajo un enfoque multidisciplinar: una experiencia práctica." p. 3. 